\title{
Using A-Train Observations to Evaluate East Pacific Cloud Occurrence and Radiative Effects in the Community Atmosphere Model
}

\author{
ElizABETH BERRY AND GERALD G. MACE \\ University of Utah, Salt Lake City, Utah
}

ANDREW GETTELMAN

National Center for Atmospheric Research, Boulder, Colorado

(Manuscript received 20 November 2019, in final form 13 March 2020)

\begin{abstract}
Using information from the A-Train satellites, the properties and radiative effects of eastern Pacific Ocean boundary layer clouds are evaluated in the Community Atmosphere Model, version 5 (CAM5), from the summer of 2007 and 2008. The cloud microphysical properties are inferred using measurements from CloudSat and CALIPSO (CC) that are then used to calculate the broadband radiative flux profiles. Accounting appropriately for sampling differences between the measurements and the simulation, evidence of the "too few, too bright" low cloud bias is found in CAM5. Single-layer low clouds have a frequency of occurrence of $42 \%$ from CC, as compared with just $29 \%$ in CAM5, and the averaged cloud radiative kernel (CRK) for the model shows stronger cooling. For stratocumulus in particular, the cooling in the model CRK is larger by a factor of 2 relative to the observations, implying an overly sensitive tropical low cloud feedback. Differences in the day/night occurrence of stratocumulus help to explain some of the difference in the CRK. The cloud-type microphysics for liquid clouds is represented reasonably well by the model, with a tendency for smaller water paths and smaller effective radii. Overall, the occurrence and CRK have partially compensating errors such that the net cooling at the top of the atmosphere for eastern Pacific low clouds is $-43 \mathrm{~W} \mathrm{~m}^{-2}$ in CAM5, as compared with $-32 \mathrm{~W} \mathrm{~m}^{-2}$ from CC. The cooling effect in the model is accomplished by fewer low clouds with a narrower range of properties, as compared with more clouds with a broader range of properties in the observation-based dataset.
\end{abstract}

\section{Introduction}

The wide range in climate sensitivity, from 2.1 to $4.7 \mathrm{~K}$ for a doubling of $\mathrm{CO}_{2}$ (Andrews et al. 2012), is due in large part to the uncertainty in cloud feedbacks (Dufresne and Bony 2008; Vial et al. 2013; Ceppi et al. 2017). It is well established that much of the intermodel spread in predicted cloud feedbacks is associated with marine boundary layer (MBL) clouds, particularly in the subtropical oceans (Bony and Dufresne 2005; Caldwell et al. 2016) but also at higher latitudes in both hemispheres (Gordon and Klein 2014). While the sign of the MBL cloud feedback is not certain, most models suggest that MBL cloud cover decreases with warming (Sherwood et al. 2014), implying a positive feedback. Part of the uncertainty in low cloud feedbacks stems from competing effects for low cloud changes (Gettelman

Corresponding author: Elizabeth Berry, betsy.berry@utah.edu and Sherwood 2016), although the dominant mechanism seems to be a drying of the planetary boundary layer due to increased mixing with drier air aloft, as the sea surface temperature rises (Qu et al. 2014). Uncertainty in climate sensitivity has also specifically been traced to the representations of cumulus by shallow convection schemes in GCMs (Zhao et al. 2016; Vial et al. 2016).

Cloud radiative kernels (Zelinka et al. 2012) have allowed for the direct calculation of cloud-type feedbacks. In addition, the kernel method allows for the feedbacks to be decomposed into components that are due to changes in cloud amount, cloud optical depth, and cloud height. For example, Zelinka et al. (2016) highlights the importance of reductions in low-level clouds, showing that the low cloud amount feedback is the single largest contributor to the spread in net cloud feedback.

Reducing the uncertainty in cloud feedbacks will require accurate simulations of clouds, and an understanding of how cloud cover and properties will change 
in a warming climate (Stevens and Bony 2013). Information from satellite measurements is helping to diagnose some of the connections between cloud properties and radiation, which can then be used to evaluate and improve models (Wang and Su 2013; Dolinar et al. 2015; Mace and Berry 2017; Winker et al. 2017). From satellite observations, a number of outstanding issues have been identified with the representation of low-level clouds in models. For example, models tend to overestimate the mean cloud liquid water path (LWP) relative to various observational datasets ( $\mathrm{Li}$ et al. 2018; Stephens et al. 2019). Despite large differences in LWP and cloud amount, climate models show good agreement in cloud radiative effects (Lauer and Hamilton 2013), suggesting that some amount of model tuning is used to achieve the constrained radiative fluxes.

The tendency for GCMs to produce low clouds that are underestimated in amount and overly reflective has been well documented. The "too few, too bright" problem was coined by Nam et al. (2012), who showed that models predict overly bright low clouds, even for a correct low cloud cover. Engström et al. (2014) also showed that GCMs have a tendency for small cloud fraction to be related to high cloud albedo, relative to MODIS and CERES. Medeiros and Nujiens (2016) evaluated cumulus clouds in the trade wind regions and found that the models generally capture the cloud radiative effect but underestimate cloud cover, relative to CERES and CALIPSO. Konsta et al. (2016) used CALIPSO data to document the lack of boundary layer clouds around the tropical belt, and the overestimate of the low cloud reflectance relative to Polarization and Anisotropy of Reflectances for Atmospheric Sciences coupled with Observations from a Lidar (PARASOL), and documented the inability of GCMs to reproduce the contrast between higher cloud reflectance observed along the eastern Pacific Ocean and the lower values over the tropical trade wind cumulus region.

The difficulty in simulating low clouds and their effects is intriguing, given the apparent simplistic nature of these clouds, compared to mixed-phase or ice clouds. For instance, because liquid clouds reside low in the atmosphere, they can more easily be studied by surface remote sensing and be measured by research aircraft. In addition, the spherical shape of liquid drops greatly simplifies the relationships between their microphysical and radiative properties. However, thin liquid clouds, with water paths of less than $100 \mathrm{~g} \mathrm{~m}^{-2}$, can be misleadingly challenging to observe because they tend to be geometrically and optically thin and broken in structure (Turner et al. 2007). Active remote sensing, with its vertically resolved measurements and small footprints, has made strides in this area. For example, Chepfer et al.
(2008) used CALIPSO data to evaluate cloudiness in a GCM and found that discrepancies in marine boundary layer clouds are more pronounced than in previous evaluations based on passive observations.

Here, we use A-Train satellite observations to evaluate low clouds simulated in the Community Atmosphere Model, version 5 (CAM5; Neale et al. 2010). Our objective is to evaluate cloud fraction, cloud brightness, cloud microphysical properties, and cloud radiative effects (CREs) in the model. To the extent that the model produces CREs that are similar to observations, does it do so for the correct reasons, or are there compensating errors that lead to good agreement for the radiation? Our findings will provide insight into the validity of predictions of low cloud feedbacks.

\section{Data and method}

In this study we primarily emphasize low-level liquid clouds, although we present results for all cloud types. We focus on a $20^{\circ} \times 20^{\circ}$ region in the east Pacific $\left(10^{\circ} \mathrm{S}-10^{\circ} \mathrm{N}\right.$, $90^{\circ}-110^{\circ} \mathrm{W}$ ) during two June through September periods (2007 and 2008). The domain is centered on the equator, with the eastern boundary along the longitude of the Galápagos Islands, and located downwind of the maximum coverage for stratocumulus along the east side of the subtropical ocean basin (Rozendaal et al. 1995). This region is characterized by the easterly trade winds and captures the stratocumulus to cumulus transition that occurs as the boundary layer and sea surface temperature increase and stratocumulus gradually transition to scattered trade cumulus (Miller et al. 1998).

For assessing clouds and their impacts, we adapt the cloud radiative kernel framework to A-Train observations and CAM5, making two main modifications. First, we evaluate present-day cloud radiative effects instead of cloud feedbacks, given the short-term record of the A-Train satellites. Second, we create cloud radiative kernels that are derived from populations of observed and simulated clouds separately to evaluate potential differences in the sensitivity of the top-of-atmosphere (TOA) radiation to cloud types in the observations and model. Using this method, we allow for differences in the observation-based CRK and the modelbased CRK. For instance, a different distribution of clouds within a given cloud-top pressure-cloud optical depth $(\mathrm{CTP}-\tau)$ bin would lead to a different value for the CRK. Differences in the resulting cloud radiative effects for the model and observations may be due to differences in cloud fraction and/or differences in the sensitivity of the TOA radiation to clouds.

\section{a. Observations}

CloudSat's cloud profiling radar (Tanelli et al. 2008), along with CALIPSO's optical lidar (Winker et al. 
2010), provides vertically resolved measurements of hydrometeor properties (Stephens et al. 2018). In this study, we harness the synergy of CloudSat and CALIPSO (hereinafter together referred to as $\mathrm{CC}$ ) to characterize liquid clouds. The lidar is particularly important for observing boundary layer clouds below $1 \mathrm{~km}$ (Henderson et al. 2013) since the radar signal is affected by scattering of the pulse from the bright ocean surface. Cloud layers are obtained from the RL-GeoProf CloudSat dataset (Mace and Zhang 2014) and are defined as a vertically continuous set of 240-m-resolution volumes that contain hydrometeors. Profiles with only one cloud layer present are identified as single-layer clouds.

The general approach used here is adapted from the method outlined in Mace (2010) as modified and implemented in Berry et al. (2019). Microphysical properties for ice cloud are obtained from the $2 \mathrm{C}$-ICE data product (Deng et al. 2015). The properties of low-level clouds that exist above $1 \mathrm{~km}$ and that are observed by the CloudSat radar are derived using a combination of radar $Z$ and optical depth from MODIS (day) that is then constrained by CERES solar fluxes or by combining radar $Z$ with LWP from AMSR-E during the night [see appendices A and B of Mace (2010)]. Two issues have limited the use of CloudSat in studying low-level clouds. First, the detection threshold of the radar at $-30 \mathrm{dBZ}$ misses some fraction of nonprecipitating low-level clouds. Second, below $\sim 1 \mathrm{~km}$ above the ocean surface, the CloudSat radar is unable to detect weaker returns associated with clouds (Marchand et al. 2008). We found that neglecting these clouds resulted in significant biases relative to CERES. Therefore, we implement a revised method that uses attenuated backscatter from CALIPSO and $94-\mathrm{GHz}$ microwave brightness temperature from CloudSat (Dobrowalski and Tanelli 2019) when a nonprecipitating (layer-maximum $\mathrm{dBZ}<-15$ ) single-layer cloud is observed at temperatures above freezing. With the additional requirement that the cloudy and nearest cloud-free column brightness temperature (TB) have a difference of at least $1 \mathrm{~K}$, the LWP is estimated using microwave brightness temperature differences between cloudy profiles and adjacent clear profiles after Mace and Protat (2018). We restrict the search for a nearby clear pixel to within $50 \mathrm{~km}$. However, given the location of our region, centered over the equatorial ocean, we would not expect large variations in the clear-sky TB. For profiles associated with continuous cloud fields for which we cannot find a clear pixel within $50 \mathrm{~km}$, we revert to the $\mathrm{Z}-\tau$ or Z-LWP retrieval. The failure to find a nearby clear pixel for TB is the sole limiting factor for $12 \%$ of liquid clouds that meet all the other criteria for the new technique. With an estimated LWP, we segregate the layers into those that are optically thin such that the ocean surface is identifiable in the CALIOP profiles (type 1) and those that are optically thick for which radar reflectivity is measured (type 2a) or for which no radar reflectivity is reported because the layer is below $1 \mathrm{~km}$ or because the layer has radar reflectivity that is below the detection threshold of CloudSat (type 2b).

For type- 1 optically thin layers, the visible optical depth is estimated using the difference in the calculated surface return that has been attenuated only for Rayleigh scattering and the lidar signal from the surface bin of the cloud-attenuated column. The method is described in Flamant et al. (2003), Josset et al. (2008), and Josset et al. (2011). With an estimate of the LWP from CloudSat TB and with an estimated layer optical depth, we are able to then estimate the layer effective radius (Stephens 1978). With the uncertainties of the LWP and optical depth estimated to be on the order of $50 \%$, the effective radius would be uncertain to something like $70 \%$. While this uncertainty is large, it allows us to distinguish between layers that might be isolated drizzle from a recently evaporated cloud or a true nonprecipitating cloud layer.

The properties of type-2a layers that have radar reflectivity, TB, and lidar attenuated backscatter near cloud top are reasonably straightforward to estimate using methods described in Mace and Protat (2018) and elsewhere. The properties of type-2b layers for which we have no radar reflectivity are more challenging. These layers are optically thick such that we are unable to use attenuation of surface reflectance to estimate optical depth. Therefore, we use the information provided by CALIPSO and the methods described by $\mathrm{Hu}$ et al. (2007) and $\mathrm{Li}$ et al. (2011) to constrain the cloud-top extinction and effective radius. These, combined with water path from $\mathrm{TB}$, allow us to estimate the column radiative properties.

For the low-cloud results presented below, $85 \%$ use the $\mathrm{Z}-\tau$ or $\mathrm{Z}-\mathrm{LWP}$ retrieval to obtain the liquid microphysical properties. For the $15 \%$ of low clouds that use the new technique, the majority of these clouds existed below $1 \mathrm{~km}$ or were below the detection threshold of CloudSat. Of these, $4.1 \%$ are type- 1 retrievals, $6.6 \%$ are type- $2 \mathrm{a}$ retrievals, $0.3 \%$ are type- $2 \mathrm{~b}$ retrievals, and $4.7 \%$ use the TB-derived LWP with an initial guess for effective radius. We note that the use of CloudSat to constrain cloud properties below $1 \mathrm{~km}$ and below the detection threshold of the radar using the TB derived from the radar receiver noise is a unique use of CloudSat; while additional development of algorithms is being pursued, this initial application enables study of a new part of the cloud occurrence spectrum that has previously only been examined with reflected sunlight. By applying these new methods, we were able to 
(a)

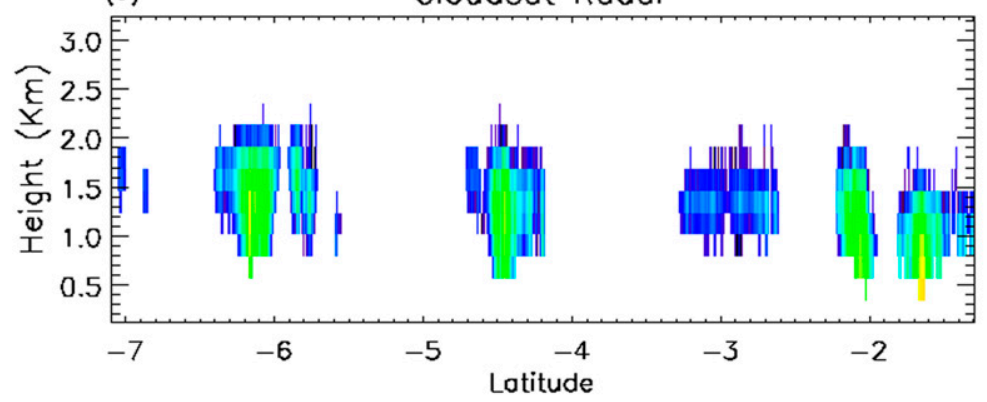

(b) CALIPSO Lidar Total Attenuated Backscatter

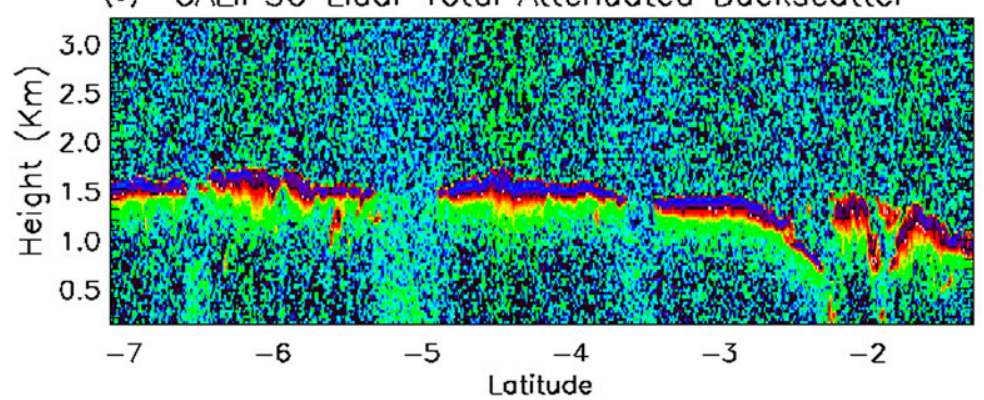

(c)

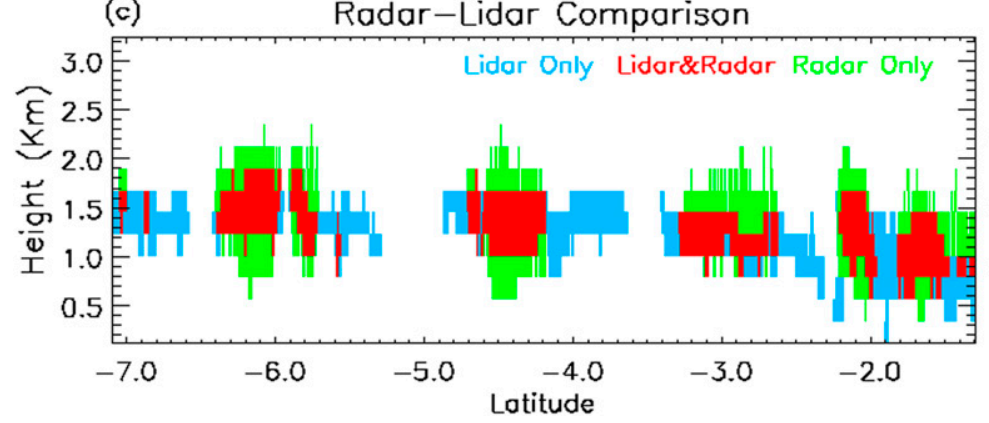

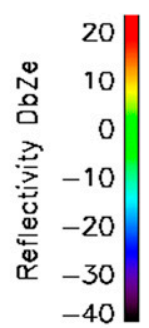

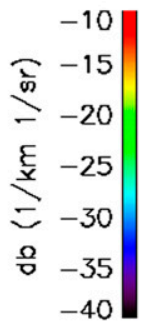

FIG. 1. (a) Radar reflectivity from CloudSat, (b) total attenuated backscatter from CALIPSO, and (c) combined radar-lidar cloud mask for a typical low cloud scene in the east Pacific domain $\left(90^{\circ}-100^{\circ} \mathrm{W}, 10^{\circ} \mathrm{S}-10^{\circ} \mathrm{N}\right)$. (d) The location of the A-Train cloud segment within the domain.

significantly improve TOA solar flux comparisons with CERES on the low end of the cloud forcing spectrum.

Cloud layer statistics from CloudSat and CALIPSO for the 2006-16 period using the Radar-Lidar Geometrical Profile Product (RL-GeoProf; Mace and Zhang 2014) show that our eastern Pacific study region experiences a total cloud coverage of $66 \%$ annually, with a multilayer cloud fraction of $19 \%$. The study region is dominated by clouds with top heights $<2 \mathrm{~km}$, making it an ideal location for studying tropical boundary layer clouds. We follow the ISCCP convention for classifying clouds as a 2D histogram, with cloudtop height on one axis and thin, moderate, and thick optical depth thresholds on the orthogonal axis. The cloud-type names we associate with the optical depth bins are just notional for convenience and are not necessarily meant to represent meteorological cloud types.

An example of a typical cloud scene is shown in Fig. 1. Approximately two-thirds (69\%) of the cloudy profiles in this scene contain stratocumulus cloud, and nearly one-third $(29 \%)$ represent cumulus cloud. From the 2C-PRECIP-COLUMN dataset (Haynes et al. 2009), 17\% of the cloud profiles are flagged as containing precipitation ( $6 \%$ possible, $5 \%$ probable, $5 \%$ certain).

\section{b. Model}

The model data analyzed in this study are from the National Center for Atmospheric Research (NCAR) CAM5. The model was run globally for 2005-08 in a standard climate configuration using observed sea surface temperatures and sea ice fraction. The simulation 
operated with a horizontal resolution of $1.9^{\circ} \times 2.5^{\circ}$ and a physics time step of $30 \mathrm{~min}$. There are 30 vertical pressure levels, with the lowest 9 levels (pressure $>763 \mathrm{hPa}$ ) corresponding to geopotential heights below $2.5 \mathrm{~km}$ for our study domain.

The stratiform cloud microphysics are represented by a two-moment scheme that predicts the mixing ratio and number concentration for four separate hydrometeor species including cloud water, cloud ice, rain, and snow (Morrison and Gettelman 2008). Cloud fraction is diagnostic and the stratus liquid cloud fraction is predicted based on relative humidity. CAM5 uses a moist PBL scheme to parameterize the eddy diffusivity based on the turbulent kinetic energy (Bretherton and Park 2009). Precipitation is diagnostic, and the autoconversion of cloud water to rain is given by Khairoutdinov and Kogan (2000), which has been shown to produce rain formation that is closer to satellite observations than other autoconversion schemes (Suzuki et al. 2015). From the shallow convection scheme (Park and Bretherton 2009), detrained condensate is added to cloud liquid using the detrained mass with an assumed mean volume radius of $8 \mu \mathrm{m}$.

The radiation scheme used in CAM5 is the Rapid Radiative Transfer Model for GCMs (RRTMG; Iacono et al. 2008; Mlawer et al. 1997) and the subgrid cloud characterization in RRTMG is treated using the maximum-random cloud overlap assumption. Aerosols are a prognostic variable and their radiative effects are included in the clear sky and cloudy calculations. Rain, however, is not included in the radiation calculations ( $\mathrm{Li}$ et al. 2014). Unlike snow, the absence of rain in the radiation calculation in GCMs does not lead to large errors (Hill et al. 2018).

\section{c. Model-observation comparison}

When comparing satellite observations and model output, one must be aware of the inherent differences in the datasets and take steps to account for those differences. Given that the $\mathrm{CC}$ observations are sunsynchronous, we sample CAM5 3-hourly instantaneous output at the time closest to the CC overpasses (0130 and 1330 UTC) to capture similar aspects of the diurnal cycle of clouds and shortwave radiative effects. Since the CC microphysical retrieval includes all hydrometeors (i.e., cloud water and rain) in the profile, a more direct comparison to the model liquid water path includes filtering out $\mathrm{CC}$ profiles that are flagged as precipitating at the surface (Li et al. 2008). In this study, all CC profiles containing rain are excluded from the comparison of the cloud microphysics. All hydrometeor profiles (including those with rain) are used in the observational results for cloud fraction and cloud radiative effects.
In terms of cloud detection, between CloudSat and CALIPSO we will observe nearly all single-layer low clouds. Optically thin clouds are observed by the lidar, while optically thicker clouds above $1 \mathrm{~km}$ are observed by the radar. A limitation of the radar and lidar is the potential inability to measure cloud below $1 \mathrm{~km}$ in scenes where the lidar has been attenuated. However, unique to this study is the use of the $94-\mathrm{GHz}$ brightness temperature, which provides an estimate of the LWP in these previously uncharacterized boundary layer clouds. Hence, the observed single-layer low cloud fraction can be directly compared to the model.

We do not expect the variability in CAM5 cloud properties to be as large as the measurements since the spatial resolution of the model $(\sim 200 \mathrm{~km} \times 200 \mathrm{~km})$ is much coarser than the $\mathrm{CC}$ observations $(1.4 \mathrm{~km} \times$ $2.1 \mathrm{~km})$, and the grid box quantities represent the average conditions over a comparatively large area. Furthermore, the cloud radiative effects from CAM5 cannot readily be attributed to specific cloud types because the grid box average cloud properties (cloud fraction, microphysics, and radiation) are the result of a mixture of clouds that are combined. To account for this and make a more consistent comparison with $\mathrm{CC}$, we apply a sampling technique to approximate the subgridscale statistics following a method that is standard in model-measurement comparison studies. Using the maximum-random overlap assumption (Jakob and Klein 1999; Collins 2001), we divide CAM5 grid boxes into 100 subcolumns based on the model cloud fraction profile (e.g., a cloud fraction of $60 \%$ at $3 \mathrm{~km}$ would result in 60 of 100 subcolumns containing cloud at that level). For each height level, the microphysical properties remain homogeneous across the cloudy subcolumns. Doing this for each vertical level in the model grid box then yields 100 subcolumns with varying cloud profiles. In terms of cloud statistics, our subcolumn method produces similar results to what a satellite simulator would accomplish, as demonstrated in Berry et al. (2019).

\section{d. Radiation}

Following the method outlined in Berry et al. (2019), the retrieved (CC) and simulated (CAM5) cloud microphysical properties (water content and $r_{e}$ ) are, respectively, used to calculate the cloud radiative properties that then serve as inputs for the radiative transfer model. The cloud radiative properties (singlescattering albedo, extinction, and asymmetry parameter) for the CC profiles and CAM5 subcolumns are determined using the same established parameterizations for liquid cloud (Slingo 1989; Kiehl et al. 1998) and ice cloud (Fu 1996; Fu et al. 1998). Atmospheric profiles of temperature and specific humidity are obtained from the European 

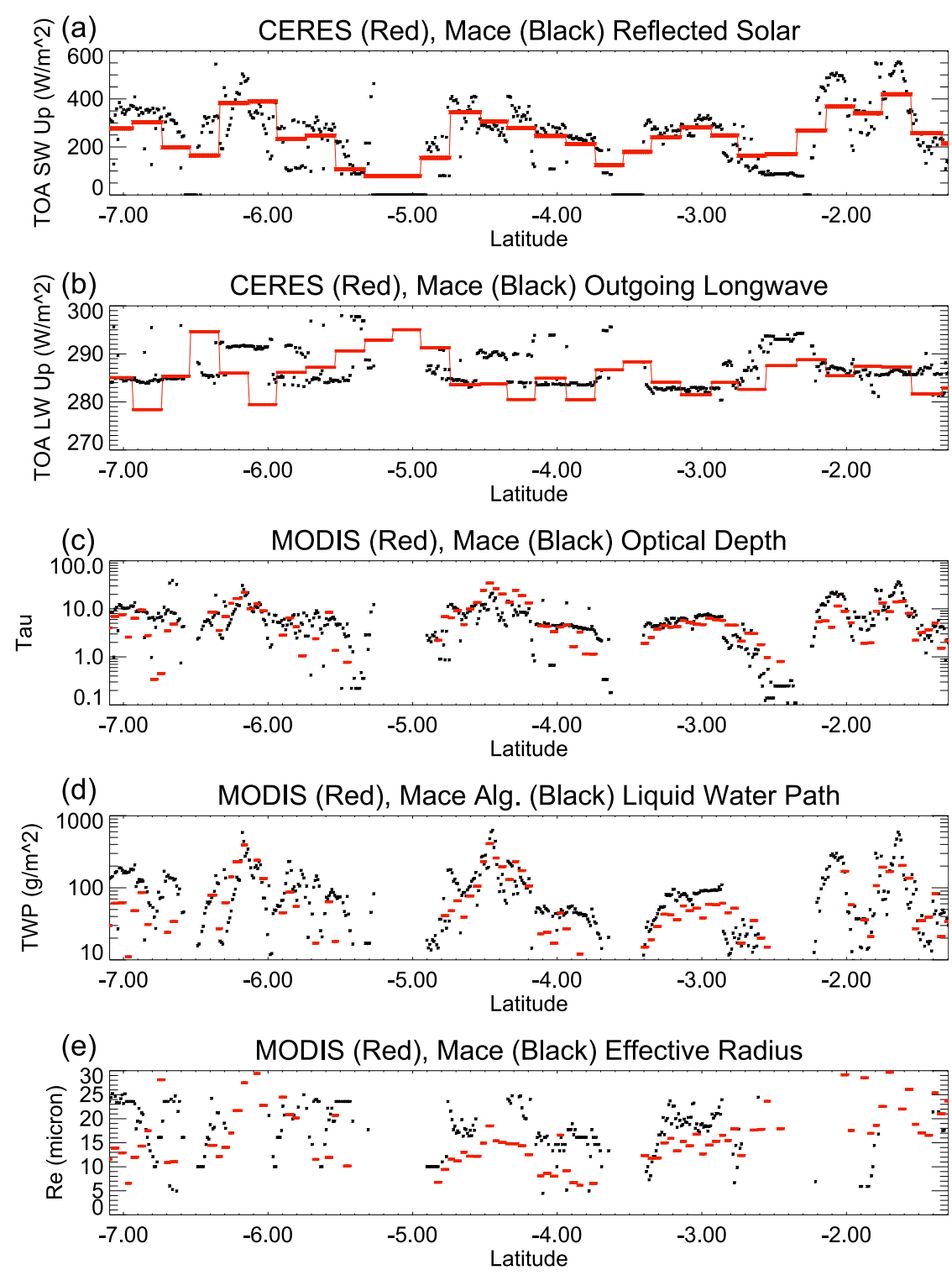

FIG. 2. Comparison of our retrieved cloud properties and radiative fluxes (black dots) with other datasets (red) for the case study presented in Fig. 1: (a) upwelling shortwave flux at the TOA, (b) outgoing longwave flux at the TOA, (c) cloud optical depth, (d) LWP, and (e) effective radius.

Centre for Medium-Range Weather Forecasts Auxiliary (ECMWF-AUX) CloudSat data product for the CC calculations and from CAM5 thermodynamic variables for the model calculations.

The same radiative transfer model is used to obtain the radiative fluxes for the observed $\mathrm{CC}$ profiles and simulated CAM5 subcolumns. The shortwave and longwave radiative fluxes are calculated with the "RAPRAD" (Toon et al. 1989; Kato et al. 2001; Mlawer et al. 1997), a two-stream rapid radiative transfer model that uses the $k$-distribution method and correlated- $k$ assumptions. The clear-sky fluxes for each profile are calculated by setting the cloud amount to zero. The cloud radiative effect is obtained by differencing the allsky and clear-sky fluxes.

Figure 2 shows the retrieved microphysical properties (optical depth, integrated water path, and layer-mean effective radius) and radiative fluxes for the $\mathrm{CC}$ case study presented in Fig. 1. Shown for comparison are estimates from other observational datasets like the Moderate Resolution Imaging Spectroradiometer (MODIS; Platnick et al. 2017) and Clouds and the Earth's Radiant 
Energy System (CERES; Kratz et al. 2014) The majority of the profiles $(526 / 600)$ in this scene contain single-layer low cloud and the new liquid phase retrieval method described above is used to obtain the microphysical properties for slightly more than half (272) of the cloud profiles. We find a substantial range in cloud properties and radiative fluxes just among these low clouds, and the A-Train retrieval captures these range well based on the comparison to the radiative fluxes. Interestingly, the A-Train retrieval correlates relatively well with completely physically independent methods to derive optical depth and liquid water path. This is much less true for the effective radius, highlighting how difficult it is to get a handle on this variable with remote sensing. On average, these low cloud layers have a LWP around $100 \mathrm{~g} \mathrm{~m}^{-2}$ and optical depth near 10 , producing a shortwave CRE of $-195 \mathrm{~W} \mathrm{~m}^{-2}$ and a longwave CRE of $8 \mathrm{~W} \mathrm{~m}^{-2}$.

To validate our approach with the model, we compare our calculated subcolumn radiative fluxes from RAPRAD, averaged within each grid box, to the internally generated fluxes from RRTMG that are created in the model run and stored in the CAM5 output, as in Berry et al. (2019). The magnitude of the average bias between our calculated radiation for the model subcolumns and CAM5 grid box radiation variables, is less than $5 \mathrm{~W} \mathrm{~m}^{-2}$ for the clear-sky and all-sky shortwave and longwave TOA fluxes. Hence our subcolumn method is able to reproduce the mean CAM5 radiative fluxes appropriately.

\section{Cloud occurrence and radiative effects results}

\section{a. Cloud occurrence}

For the period under study, the CC observations give a total cloud fraction of $77 \%$ in the east Pacific region, which agrees well with previous seasonal estimates for this region (Mace et al. 2009; Mace and Wrenn 2013). Multilayer clouds are present in $25 \%$ of all CC profiles, and cloud-free columns represent $23 \%$ of profiles. The total cloud fraction in CAM5 is very similar, at $74 \%$, with $28 \%$ of all subcolumns containing multiple cloud layers, and $26 \%$ of subcolumns being cloud-free. We find that single-layer clouds are slightly less common at the time of the daytime overpass relative to the nighttime overpass (43\% vs $57 \%$ for CC and $46 \%$ vs $54 \%$ for CAM5).

In this study we evaluate profiles/subcolumns with single-layer clouds, such that we can assign the radiative effects to a specific cloud type. Model subcolumns containing single-layer clouds are defined as having only one cloud layer in the vertical and are identified using the cloud fraction profile $(0=$ no cloud; $1=$ cloud $)$. In addition, we evaluate the single-layer cloud fraction for cloud types defined as a function of cloud-top height (CTH) and $\tau$, similar to cloud-type definitions for the International Satellite Cloud Climatology Project (ISCCP; Rossow and Schiffer 1999). The resulting cloud fraction histograms for single-layer clouds are shown in Fig. 3 (left panels) and summarized in Table 1. CC observes more $(53 \%)$ single-layer clouds relative to CAM5 subcolumns (46\%). In terms of CTH, the single-layer cloud fraction is dominated by low-topped clouds in both the model and observations. In terms of optical depth, cloud layers with moderate optical depth occur most frequently in both the models and observations.

The histograms of cloud fraction reveal large differences for low cloud types. Most notably, the model produces much fewer single-layer low clouds (29\%) as compared with that observed by CC (42\%). For instance, single-layer cumulus is observed to occur $7 \%$ of the time in the $\mathrm{CC}$ observations, although it is almost nonexistent (1\%) in CAM5 subcolumns. In addition, stratocumulus are also more common in the CC observations $(28 \%)$ compared to CAM5 subcolumns $(17 \%)$. The relatively smaller fraction of cumulus and stratocumulus in the model could be related to issues with the stratocumulus to cumulus transition [as noted in Kay et al. (2012)], such as a geographic bias of where these clouds are located.

Overall, CAM5 overestimates the most optically thick clouds, while underestimating optically thinner clouds, producing about $70 \%$ of the observed clouds that have thin (9\% for CAM5 vs 13\% for CC) and intermediate (21\% for CAM5 vs 31\% for CC) optical depths, and nearly double the amount of clouds with the largest optical depths (16\% for CAM5 vs $9 \%$ for CC). In particular, low clouds with thin and intermediate optical thickness (cumulus and stratocumulus) are underestimated by about one-half (18\% for CAM5 vs 35\% for CC), while the most optically thick low cloud, stratus, has a greater occurrence $(11 \%)$ in the model relative to observations ( $7 \%)$. These results agree well with those of Zhang et al. (2005), who compared GCMs with ISCCP and CERES data, finding evidence of too-few low clouds and low clouds that are too bright.

\section{b. Cloud radiative kernels}

To assess the radiative effects by clouds types, we create cloud radiative kernels, which describe the sensitivity of the TOA radiation $R$ to changes in cloud fraction $(\mathrm{CF})$, following $\mathrm{CRK}=\partial R / \partial \mathrm{CF}$. Like $\mathrm{CF}$, the cloud radiative kernel is derived for single-layer clouds as a function of CTP and $\tau$, and it has units of watts per meter squared per percentage point. As in Berry et al. (2019), we create observation- and model-derived CRKs. 

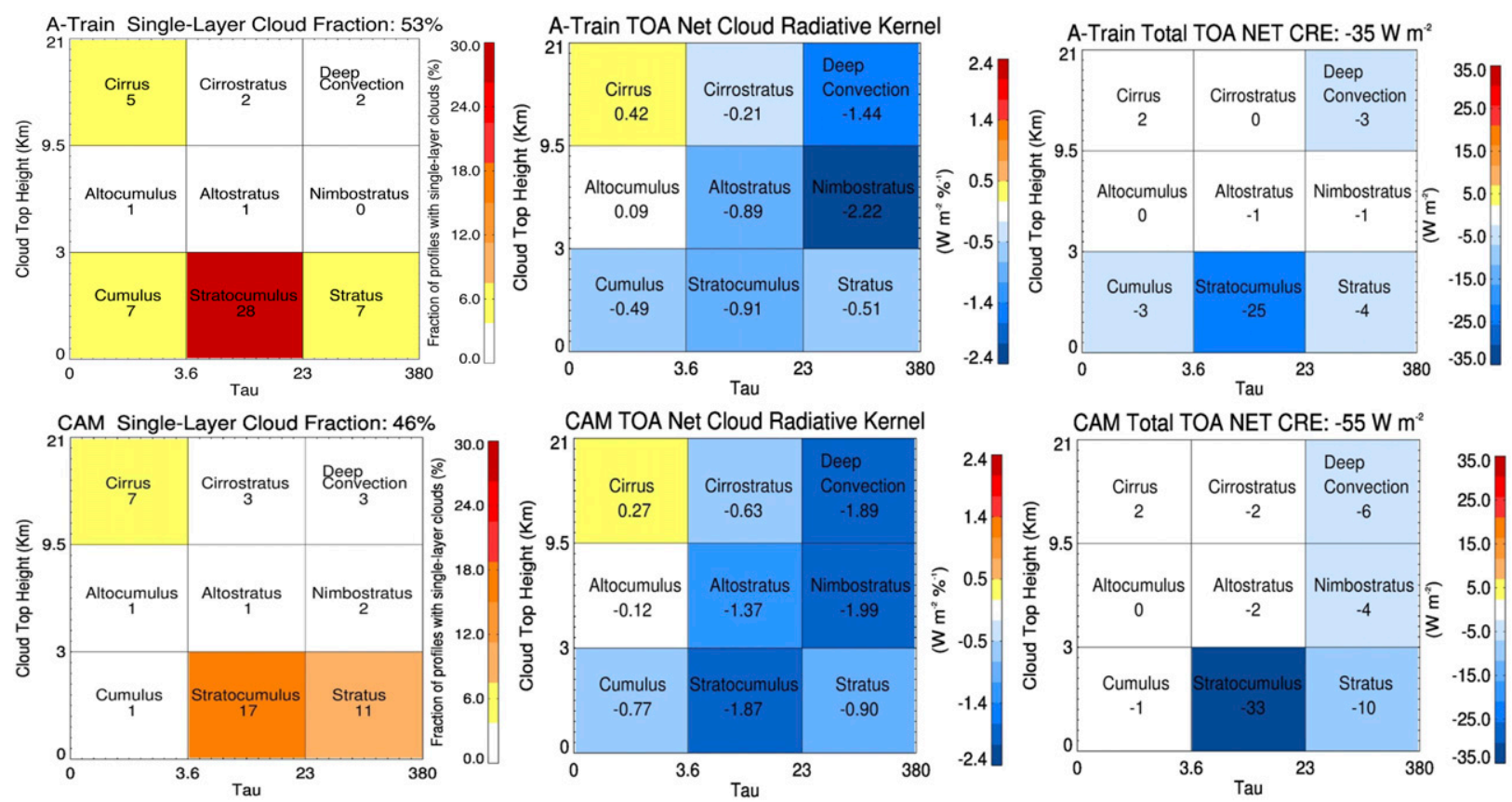

FIG. 3. (left) Single-layer cloud fraction histogram (CF), (center) TOA net cloud radiative kernel (CRK), and (right) TOA net cloud radiative effect $(R=\mathrm{CF} \times \mathrm{CRK})$ as a function of cloud optical depth and cloud-top height for (top) the observed A-Train dataset and (bottom) CAM5.

The radiative fluxes for the observed and modeled clouds are calculated in a consistent manner, using the same parameterization for radiative properties and same radiative transfer model. Our data-derived CRKs represent the average cloud radiative effects, based on all the observed/modeled single-layer clouds that occur in a given cloud-type bin. Therefore, the magnitude of the observation-based and model-specific radiative kernels depends on their respective cloud microphysical properties and temporal statistics.

The net cloud radiative kernels for CC and CAM5 are presented in Fig. 3 (middle panels). Not shown is the longwave (LW) kernel, since the LW effects of the mostly commonly occurring low clouds are very small, and the shortwave (SW) kernel, since it is very similar to the net CRK for low cloud. The net CRKs show cooling effects decreasing with $\mathrm{CTH}$ and increasing with optical depth, with the exception of stratus, which is discussed further below. For optically thin clouds $(\tau<3.6)$, we find good agreement between the model and observations, with the net CRK ranging from -0.77 cooling in cumulus to $0.42 \mathrm{~W} \mathrm{~m}^{-2} \%^{-1}$ warming for cirrus. The largest differences in the net CRK occur for low clouds (CTH $<3 \mathrm{~km}$ ), with the model showing much stronger cooling compared to the observations. For stratocumulus, the most commonly occurring cloud type, the cooling in the model CRK is larger by a factor of 2 than the observation-based CRK $\left(-1.87 \mathrm{~W} \mathrm{~m}^{-2} \%^{-1}\right.$ for CAM5 vs $-0.91 \mathrm{~W} \mathrm{~m}^{-2} \%^{-1}$ for $\left.\mathrm{CC}\right)$. Overall, the differences for the most commonly occurring low cloud types tell us

TABLE 1. Occurrence frequencies (\%) for single-layer clouds in the CloudSat-CALIPSO (CC) dataset and CAM5 subcolumns, using cloud-type definitions based on cloud-top height (CTH) and optical depth $\tau$.

\begin{tabular}{lccrr}
\hline \hline \multicolumn{1}{c}{ Cloud type } & CC absolute & CAM5 absolute & CC relative & CAM5 relative \\
\hline High $(\mathrm{CTH}>9.5 \mathrm{~km})$ & 9 & 13 & 17 & 28 \\
Middle $(3<\mathrm{CTH}<9.5 \mathrm{~km})$ & 2 & 4 & 4 & 9 \\
Low $(\mathrm{CTH}<3 \mathrm{~km})$ & 42 & 29 & 49 & 100 \\
Total & 53 & 9 & 25 & 100 \\
Thin $(\tau<3.6)$ & 13 & 21 & 58 & 19 \\
Intermediate $(3.6<\tau<23)$ & 31 & 16 & 17 & 36 \\
Thick $(\tau>23)$ & 9 & 46 & 100 & 100 \\
Total & 53 & & \\
\hline
\end{tabular}


that the model is making clouds that are brighter than clouds in the real atmosphere.

\section{c. Cloud radiative effects}

We use our CRKs to calculate the cloud radiative effects in the observations and model following, $R=$ $\mathrm{CRK} \times \mathrm{CF}$, where $R$ gives the contribution of each cloud type to the TOA radiation $\left(\mathrm{W} \mathrm{m}^{-2}\right)$. The calculated cloud radiative effects are therefore a function of the cloud properties and cloud occurrence. Since we are using the kernel approach, we can identify discrepancies in observed and modeled CRK and CF for individual cloud types.

From Fig. 3 (right panels), the net CRE for the east Pacific, due to single-layer clouds, shows more cooling from CAM5 $\left(-55 \mathrm{~W} \mathrm{~m}^{-2}\right)$ relative to the $\mathrm{CC}$ retrieval $\left(-35 \mathrm{~W} \mathrm{~m}^{-2}\right)$. Much of this difference is due to stratocumulus and stratus clouds, which exhibit differences in $\mathrm{CF}$ and radiative cooling. Some of the differences in $\mathrm{CF}$ and CRK tend to compensate each other. For instance, despite the greater sensitivity to cumulus in CAM5, cumulus observed by $\mathrm{CC}$ have a stronger cooling effect in the region, given their frequency of occurrence. Overall, it is stratocumulus clouds that produce the most cooling in this region in both the $\mathrm{CC}$ observations and CAM5, owing to the fact that they are the most frequent cloud type. However, the cooling due to stratocumulus is a bit weaker in the $\mathrm{CC}$ retrieval $\left(-25 \mathrm{~W} \mathrm{~m}^{-2}\right)$ than in CAM5 $\left(-33 \mathrm{~W} \mathrm{~m}^{-2}\right)$.

For cumulus and stratocumulus, we find that the low cloud fraction is underestimated, and the sensitivity to the TOA radiation is overestimated in CAM5, relative to the $\mathrm{CC}$ retrieval. For the purposes of radiative balance, it would make sense that a difference in cloud fraction would need to be offset by a difference in the CRK. Our findings are further evidence of the "too few, too bright" tropical low cloud bias in models. Beyond low clouds, cirrus are the next most common single-layer cloud type in this region, and their occurrence and radiative effects show good agreement between CAM5 and CC, similar to the results shown in Berry et al. (2019).

To further investigate these differences in CRE, we compare the TOA upwelling solar flux between CERES and $\mathrm{CC}$ and between CAM5 and CC in Fig. 4. First, the upwelling solar flux retrieved from $\mathrm{CC}$ is compared to the upwelling solar flux measured by CERES (top panel). For this comparison, we determine the average radiative fluxes for all CloudSat profiles within each CERES footprint (from RAPRAD) and compare that with the CERES radiative fluxes. Overall, A-Train is slightly dimmer than CERES, with a mean bias of $6 \mathrm{~W} \mathrm{~m}^{-2}$ in reflection, which is good agreement, considering that the CERES footprints represent a larger
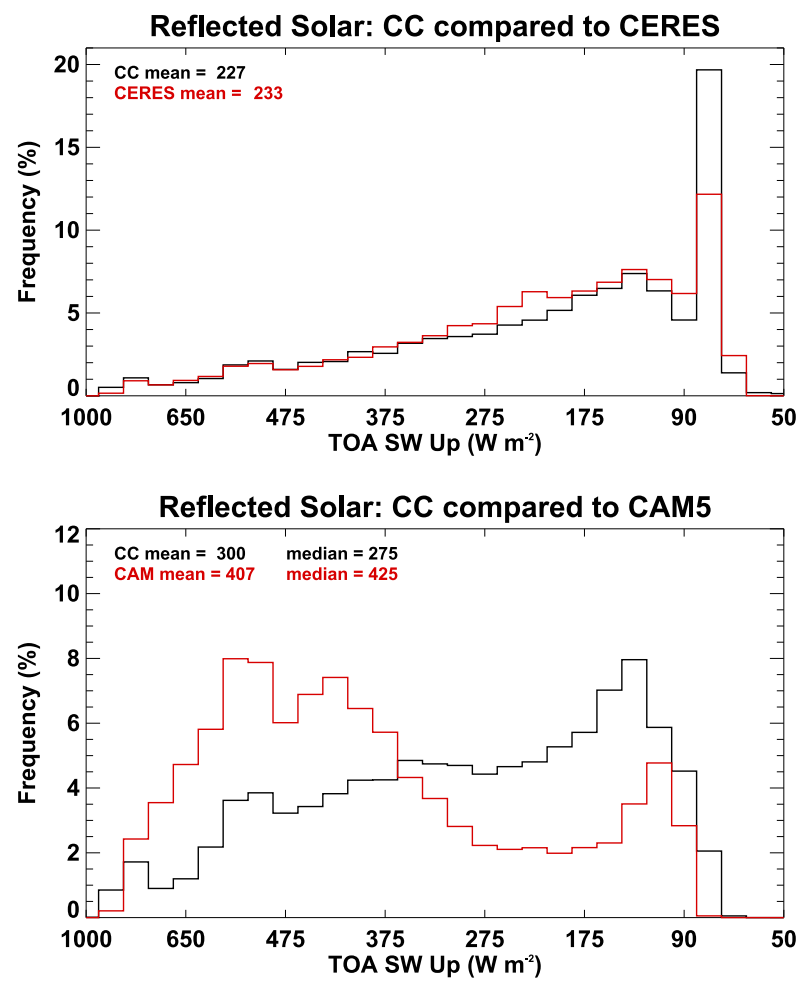

FIG. 4. TOA upwelling shortwave flux (SW up) comparisons for the study period (June-September 2007 and 2008) and domain (east Pacific): (top) distribution of reflected solar measured from CERES footprints (red; $n=14118$ ) and retrieved from A-Train profiles averaged to the footprints (black), and (bottom) distribution of reflected solar for single-layer clouds, calculated from CAM subcolumns (red; $n=2.4 \times 10^{6}$ ) and retrieved from A-Train profiles (black; $n=2.5 \times 10^{5}$ ). Noted are the mean and median values for the distribution of TOA SW up.

area (20-km diameter) than the averaged A-Train profiles. The A-Train does have a larger peak in upwelling TOA SW at $80 \mathrm{~W} \mathrm{~m}^{-2}$, associated with the reflectance of the ocean surface. This is due to the occurrence clear-sky A-Train profiles within CERES footprints that are partly cloudy. Second, we compare the distributions of the upwelling solar flux for single-layer clouds observed by CC and simulated by CAM5 (bottom panel). Overall, CAM5 single-layer clouds are brighter than $\mathrm{CC}$ observed clouds by an average of $\sim 100 \mathrm{~W} \mathrm{~m}^{-2}$ during the daytime. While the shape of the PDF for A-Train profiles looks similar to that of CERES (top panel), for CAM5 it does not. The distribution of reflected solar for CAM5 is fundamentally different from both observational datasets, in large part due to differences in cloudtype occurrence. The CAM5 distribution is composed of relatively much more optically thick clouds with $\tau>23$ (35\% of single-layer clouds) compared to CC (17\% of single-layer clouds), as noted in Table 1 . Besides firstorder differences in cloud occurrence, the SW reflection 

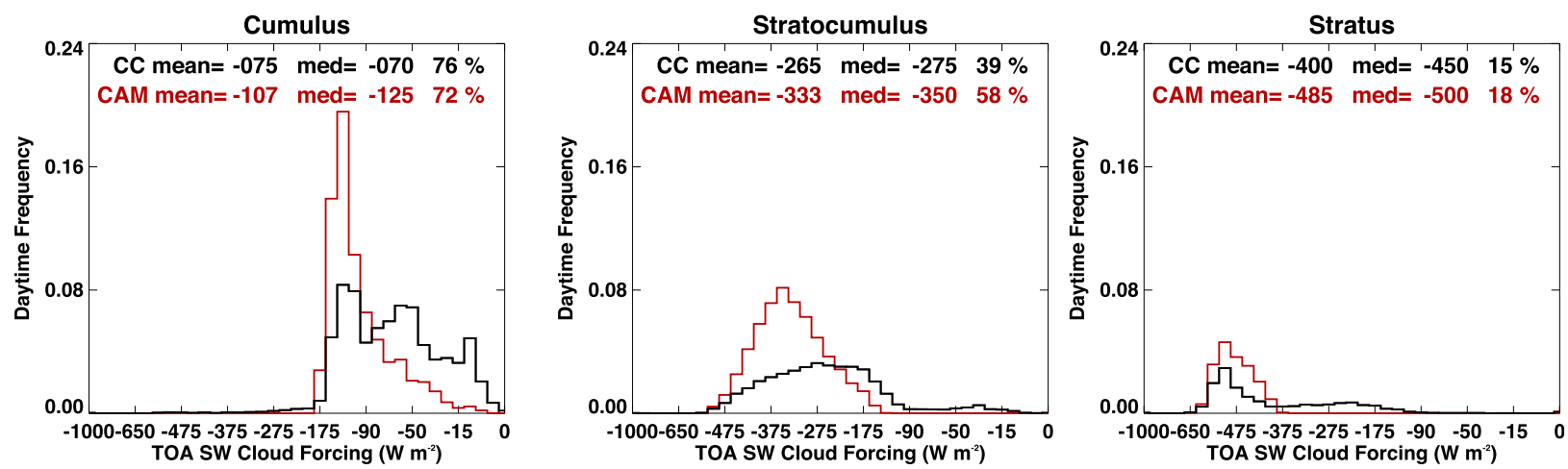

FIG. 5. The distribution of TOA shortwave CRE within each low cloud-type bin at the daytime overpass for single-layer clouds in the CC dataset (black) and CAM5 (red). The mean and median CRE values ( $\left.\mathrm{W} \mathrm{m}^{-2}\right)$ are noted for each curve, along with the relative frequency of daytime clouds.

for clouds in CAM5 could also be larger because of differences in cloud microphysical properties.

\section{Low cloud results}

\section{a. Day/night effects}

In terms of differences in the CRKs, another possible explanation may be differences in the day/night occurrence frequencies, since our data-based CRKs represent the average radiative effects from clouds that are sampled twice daily. We investigate this by showing the distribution of TOA SW cloud forcing, with daytime and nighttime effects separated, in Fig. 5. First, in terms of the day/night occurrence frequencies, we find that low clouds tend to show evidence of a diurnal cycle. As low cloud optical depth increases, occurrence at the nighttime overpass increases in both the model and observations. This agrees well with previous literature on the diurnal cycle of marine low clouds, in which stratocumulus coverage peaks in the early morning hours before sunrise, while cumulus clouds have an increasing frequency during the day (Wood 2012). Cumulus tend to occur more frequently during the day $(76 \%$ in $\mathrm{CC} ; 72 \%$ in CAM5), whereas stratus tend to occur more frequently at night ( $85 \%$ in CC; $82 \%$ in CAM5), which explains the weaker than expected cooling for stratus in the CRKs. The day/night frequencies of stratocumulus differ between the observations and model, with $\mathrm{CC}$ observing a larger nighttime fraction (61\%) and CAM5 observing a smaller nighttime fraction (42\%). This larger daytime fraction for CAM5 stratocumulus contributes to a stronger cooling in the model CRK.

Putting aside differences in the day/night fraction, we can examine just the daytime mean SW cloud forcing. The mean daytime SW cloud forcing increases with increasing optical depth, from $-75 \mathrm{~W} \mathrm{~m}^{-2}$ for CC cumulus $\left(-107 \mathrm{~W} \mathrm{~m}^{-2}\right.$ for CAM5) to $-265 \mathrm{~W} \mathrm{~m}^{-2}$ for CC stratocumulus ( $-333 \mathrm{~W} \mathrm{~m}^{-2}$ for CAM5) to $-400 \mathrm{~W} \mathrm{~m}^{-2}$ for CC stratocumulus $\left(-485 \mathrm{~W} \mathrm{~m}^{-2}\right.$ for CAM5). It is striking that this daytime-only comparison reveals more reflection by each single-layer low cloud type in CAM5 than in CC. This suggests that the population of low clouds in the model tends to be optically thicker and/or to have microphysical properties that differ from the $\mathrm{CC}$ retrieval, such that they produce more solar reflection. Although the high cloud types are not shown in Fig. 5, note that the differences in the CRK for deep convection and nimbostratus are mostly related to differences in the day/night cloud fractions, since the daytime SW forcings for these cloud types agree reasonably well.

\section{b. Microphysics}

In addition to time-of-day differences, differences in the CRKs could be related to differences in the cloud microphysics. In Table 2 we present a comparison of the low cloud properties (LWP, optical depth, and effective radius) between CAM5, all CC clouds, and nonprecipitating

TABLE 2. Mean properties for single-layer low clouds (CTH $>3 \mathrm{~km}$ and $\tau<166)$. CC-All is all CloudSat-CALIPSO observed low clouds, and CC NP are nonprecipitating observed low clouds.

\begin{tabular}{lccccr}
\hline \hline & Frequency & LWP $\left(\mathrm{g} \mathrm{m}^{-2}\right)$ & CF-normalized LWP $\left(\mathrm{kg} \mathrm{m}^{-2}\right)$ & Optical depth & Effective radius $(\mu \mathrm{m})$ \\
\hline CC-All & $41 \%$ & 138.2 & 0.34 & 14.5 & 15.5 \\
CC NP & $32 \%$ & 109.9 & 0.34 & 13.1 & 13.2 \\
CAM5 & $26 \%$ & 114.5 & 0.44 & 22.3 & 9.0 \\
\hline
\end{tabular}


(NP) CC clouds. For NP CC, approximately $30 \%$ of the CC stratocumulus and stratus have been screened out due to possible, probable, or certain precipitation. The LWP for all CC low clouds is $25 \%$ higher than NP CC low clouds. While the effective radius of all $\mathrm{CC}$ low clouds is also about $17 \%$ higher than the respective cloud-only values. These differences between all CC liquid clouds and NP CC liquid clouds show good agreement with similar results for MODISderived cloud properties (Christensen et al. 2013).

In comparing the model low clouds to the NP CC clouds, we find that CAM5 has a slightly higher mean LWP of $115 \mathrm{~g} \mathrm{~m}^{-2}$, as compared with a mean LWP of $110 \mathrm{~g} \mathrm{~m}^{-2}$ from the observations, whereas the low cloud mean effective radius in CAM5 tends to be smaller $(9 \mu \mathrm{m})$ relative to the CC NP observations $(13 \mu \mathrm{m})$. This observed value is a bit lower than results from Mülmenstädt et al. (2015), who report mean effective radii of $18-20 \mu \mathrm{m}$ from MODIS for nonraining single-layer clouds in the tropics. However, the MODIS mean liquid effective radius (re_liq) has been shown to be 1-2 $\mu \mathrm{m}$ higher for stratocumulus (Painemal and Zuidema 2011) and 7-12 $\mu \mathrm{m}$ higher for trade wind clouds (Haney 2013).

Another measure in Table 2 examines the LWP normalized by the cloud fraction. Using this, McCoy et al. (2016) found that GCMs generally overestimate the cloud-fraction-normalized LWP when compared to MODIS and they found a positive correlation between the cloud-fraction-normalized LWP and SW up in the tropics. We find similar results with our dataset. The LWP normalized by NP single-layer cloud fraction is $0.34 \mathrm{~kg} \mathrm{~m}^{-2}$ for CC and $0.44 \mathrm{~kg} \mathrm{~m}^{-2}$ for CAM5.

Shown in Fig. 6 are the distributions of cloud microphysical properties as a function of low cloud type for CAM5 and CC NP clouds. Overall, CAM5 does a fair job of representing the cloud-type microphysics (optical depth, integrated liquid water content, and liquid effective radius). However, there are some important differences.

We find that the mean of the LWP distribution for each low cloud type tends to be underestimated by CAM5, whereas the same statement is not true for the median LWP, revealing that the $\mathrm{CC}$ distributions of LWP tend to be skewed. However, the LWP statistics from Table 2 reveal that for all NP low clouds types combined, the $\mathrm{CC}$ retrieval has a slightly smaller mean LWP, compared to CAM5. Hence when the cloud occurrence is taken into account, CAM5 produces a larger mean low-cloud LWP relative to CC. However, when we examine the mean properties of the individual cloud types, the LWPs are underestimated by the model. In this sense, comparing only the overall mean low-cloud LWP will mask compensating errors in cloud-type LWP and occurrence, giving a false impression about the models' ability to represent the LWP for low clouds. For instance, it is not that CAM5 tends to produce larger cloud-type LWPs, but rather that CAM5 produces less of the optically thinner cloud layers, including cumulus that are largely missing, and more of the optically thick stratus type (which is seen prominently in the PDFs of LWP for stratus). Therefore, partitioning by cloud type and looking at the PDFs of LWP provides a more detailed and insightful comparison of LWP in the model.

Similar to LWP, the mean liquid effective radius (re_liq) for each low cloud type tends to be slightly lower in CAM5. The liquid effective radius estimated from CC tends to decrease as cloud optical depth increases. Meanwhile, the mean value of re_liq for CAM5 is consistently $8-9 \mu \mathrm{m}$ across the low cloud types, although the model PDFs of re_liq are different for each low cloud type. The persistence of this mean value of re_liq across the cloud types may be indicative of the shallow cumulus convection scheme at work, since it detrains condensate at a prescribed size of $8 \mu \mathrm{m}$.

Interestingly, taken together, CAM5 microphysics produce similar statistics of cloud optical depth for each low cloud type. For the most commonly occurring low cloud type, stratocumulus, there are some notable differences in the microphysics. CAM5 exhibits a smaller range in cloud liquid effective radius (maximum $16 \mu \mathrm{m}$ ). Also the shape of the LWP distribution for stratocumulus is different, with LWP being skewed toward smaller values $\left(\right.$ mean $=70 \mathrm{~g} \mathrm{~m}^{-2}$; median $=80 \mathrm{~g} \mathrm{~m}^{-2}$ ) in CAM5, relative to the CC retrieval, which is skewed toward larger values $\left(\right.$ mean $=104 \mathrm{~g} \mathrm{~m}^{-2}$; median $=80 \mathrm{~g} \mathrm{~m}^{-2}$ ).

The results for the cloud microphysics comparison should be put in context of how the model handles these clouds. Cumulus clouds (and likely some fraction of stratocumulus, as defined in this study) are parameterized by the shallow convective scheme, while the stratiform clouds are parameterized by the microphysics scheme. Hence the clouds handled by the shallow convective scheme have a diagnosed LWP and specified effective radius. The stratocumulus results presented here may be due to a hybrid of clouds produced with the two different parameterizations, which may explain some of the differences we find, like the shape of the LWP distribution.

\section{c. Radiative effects as a function of optical depth}

To further diagnose the connections between clouds and radiation, we examine which clouds specifically are responsible for the majority of the SW cooling effects, and are therefore radiatively most important, in the observations and model. Figure 7 shows single-layer low cloud properties and calculated radiative effects as a function of optical depth for the model subcolumns and 

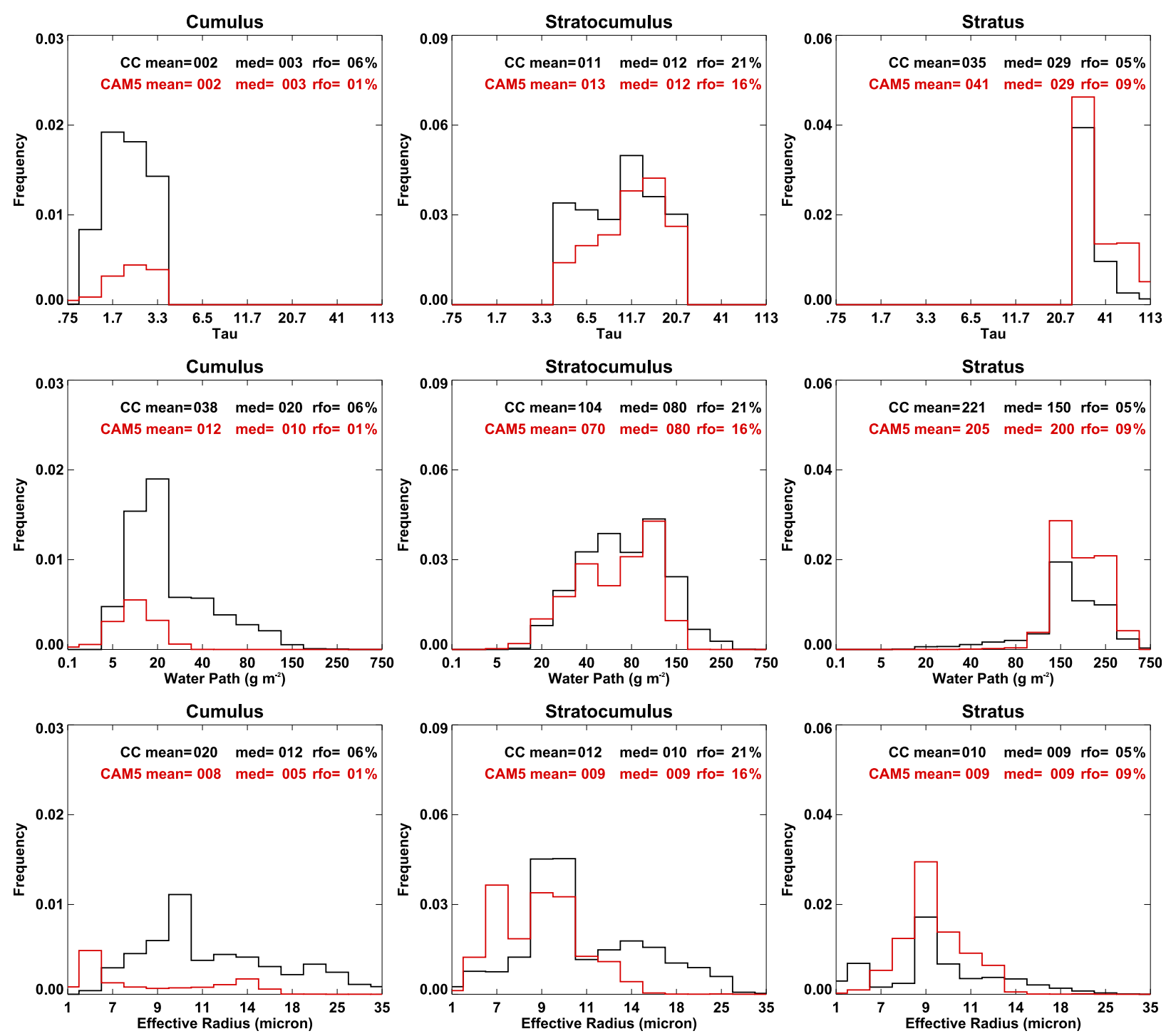

FIG. 6. Distributions of nonprecipitating cloud properties_-(top) optical depth, (middle) water path, and (bottom) effective radius-for each low cloud type: (left) cumulus, (middle) stratocumulus, and (right) stratus for the CC dataset (black) and CAM5 (red). The area under the curves sums to the fraction of profiles/subcolumns in that particular cloud type. The frequency of occurrence, along with the mean and median values of the cloud property distributions, is noted on each panel.

observations. The left panels show the distributions of optical depth, which tend to be skewed toward larger values for all times (mostly at night). The mean optical depth for the distribution of CAM5 low clouds is larger (21) compared to the CC observations (14), owing to the fact that CAM5 produces fewer cumulus and more stratus. Additionally, the low clouds in CAM5 have a 50/50 day/night ratio, while the low clouds in the CC observations are a little more likely to occur at the nighttime overpass $(40 \%)$ than in daytime $(60 \%)$.

Shown in the middle panels of Fig. 7 are the TOA net CRKs, as a function of optical depth, for observed and modeled low clouds. While we see a similar pattern for changes in the CRKs as the low cloud optical depth increases, the magnitude of the sensitivity is larger in CAM5. The daytime-only CRKs show increasing cooling with increasing optical depth, up to an optical depth around 20. The overall CRK shows cooling increasing up to an optical depth around 6, and then decreasing cooling as the optical depth increases beyond about 16 in both CAM5 and CC retrieval. This occurs because the fraction of nighttime clouds increases with increasing optical depth as shown in Figs. 5 and 7 (left panels).

When we weigh the TOA net CRK by the cloud occurrence, we obtain the net CRE as a function of low cloud optical depth (Fig. 7, right panels). Single-layer 

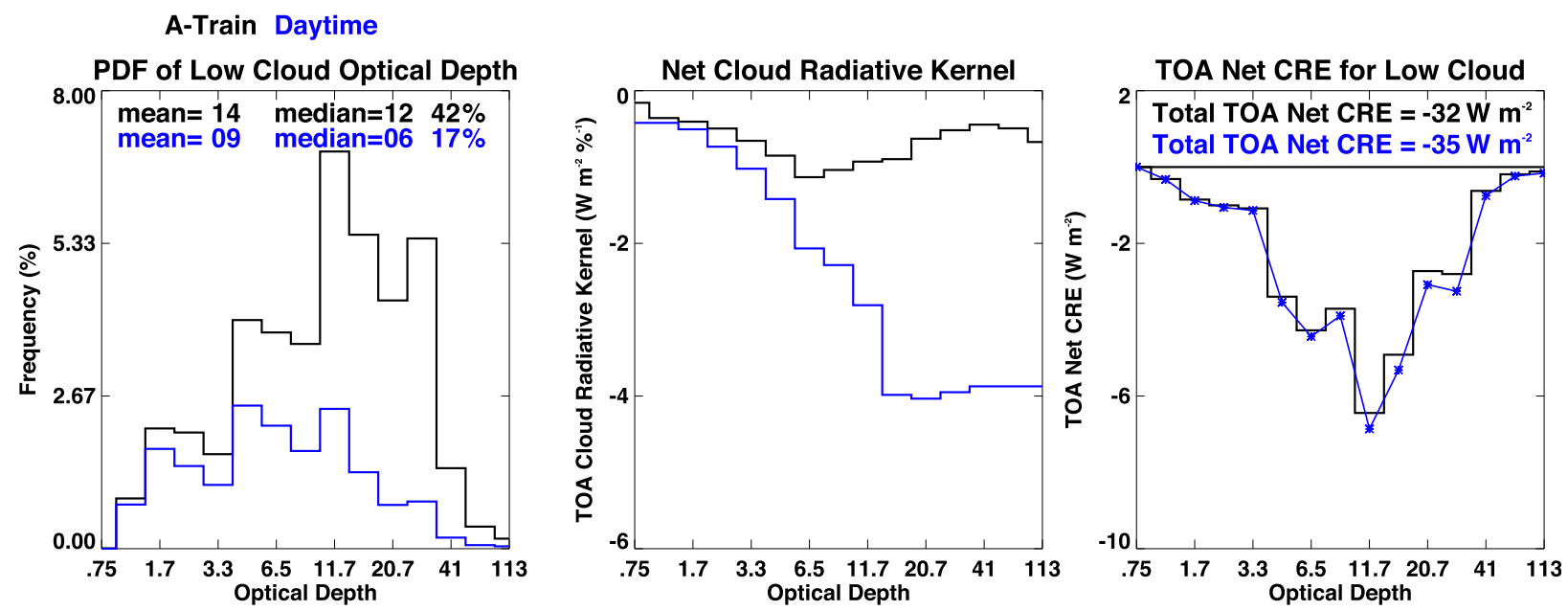

CAM5 Daytime
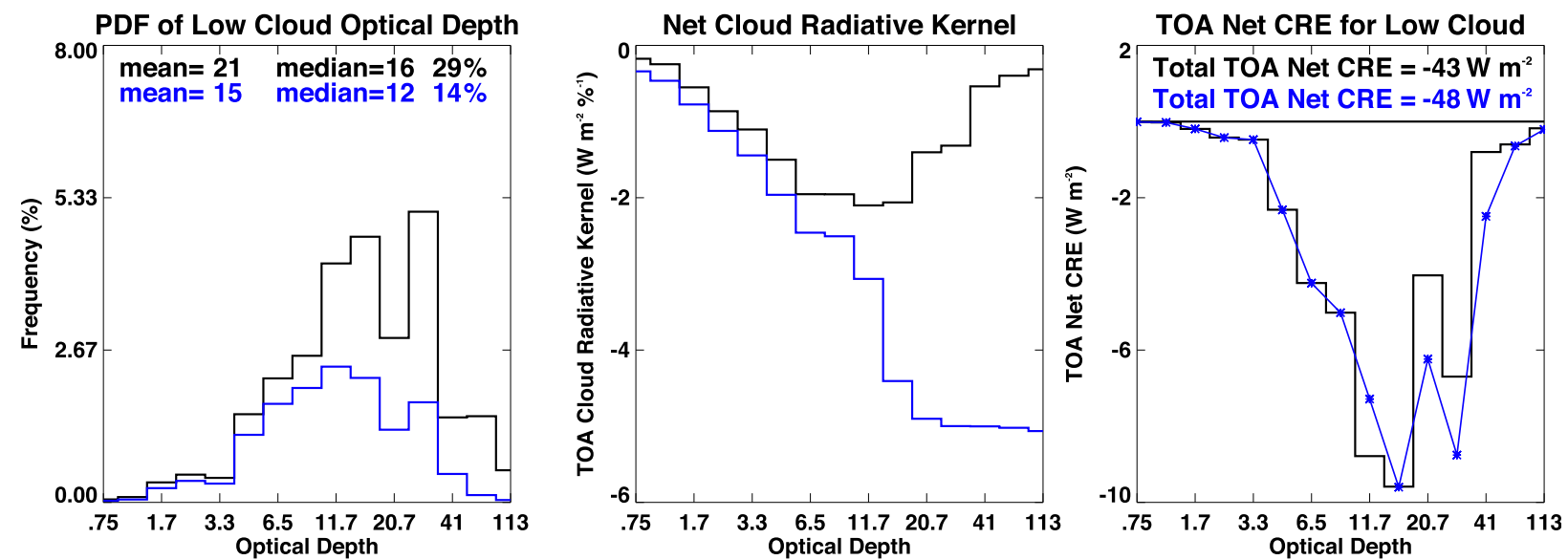

FIG. 7. Distribution of optical depth and cloud radiative effects for single-layer low clouds $(\mathrm{CTH}<3 \mathrm{~km})$ in (top) the A-Train dataset and (bottom) CAM5. Daytime-only is shown in blue; all is in black. (left) The corresponding PDFs of cloud optical depth; noted are the mean and median $\tau$ and relative frequency of single-layer low clouds. (center) TOA net CRK as a function of $\tau$. (right) The resulting TOA net cloud radiative effects (frequency $\times$ CRK) and the summed effect of all single-layer low clouds.

low clouds in CAM5 produce a larger TOA net cooling effect $\left(-43 \mathrm{~W} \mathrm{~m}^{-2}\right)$ than do single-layer low clouds in the $\mathrm{CC}$ observations $\left(-32 \mathrm{~W} \mathrm{~m}^{-2}\right)$. Overall, stratocumulus is the cloud type that is most important radiatively, given their frequency of occurrence and cooling effects. In particular, we find that stratocumulus clouds, with an optical depth of 10-20, contribute the most to the TOA radiative cooling in both the model and observations. However, overall, the cooling in CAM5 is accomplished by more optically thick clouds that occur over a narrower range of optical depths. CAM5 low clouds produce a stronger cooling for the region $\left(-43 \mathrm{~W} \mathrm{~m}^{-2}\right.$ for CAM5 vs $-32 \mathrm{~W} \mathrm{~m}^{-2}$ for CC), despite the fact that the model has far fewer single-layer low clouds ( $29 \%$ for CAM5 vs $42 \%$ for CC). In this sense, CAM5 overcompensates for having too few low clouds of thin and intermediate optical depths by having more optically thick low clouds (stratus), and producing low clouds that are brighter than those observed by CC.

The daytime CRK tends to reach a minimum in forcing beyond optical depth of approximately 15 in both the model and the observations (Fig. 7), As demonstrated in Oreopoulos and Platnick (2008), changes in liquid cloud radiative effects due to changes in optical depth are nonlinear, with albedo increasing up to an optical depth of 13 . Hence changes in cloud liquid water path and effective radius - the bulk features that would tend to change the optical depth-would have little effect on the CRE for a given cloud coverage. Since the CAM5 clouds occupy this domain much more than the observations ( $42 \%$ of daytime low clouds in the model exist at optical depth greater than $\sim 15$ compared to $18 \%$ 
of the observed clouds), any feedbacks associated with these clouds could most easily be realized by changing low cloud coverage while changes to bulk cloud properties would have minimal effect on the CRE and would not be realized as an optical depth feedback (G. L. Stephens 2020, personal communication).

\section{Conclusions}

Here we take advantage of the synergy of available in the A-Train for characterizing liquid clouds in the east Pacific and use that information to evaluate these clouds in CAM5. Using the kernel technique, we have quantified the low cloud radiative effects, and how these radiative effects are achieved by liquid clouds observed in nature and by liquid clouds simulated by the model. Our goal has been to determine to what extent the model is able to replicate the observed liquid clouds properties and radiative cooling.

Overall, we find that CAM5 reasonably simulates the shapes of the distributions for cloud-type microphysics. While the model produces brighter low clouds with stronger CRE, the ranges of SW CRE and trends in SW cooling increasing with cloud-type optical depth are reasonably represented by the model. The challenge for the model lies in reproducing small-scale distributions with coarse simulations.

In terms of cloud occurrence, cumulus and stratocumulus are substantially underpredicted by the model ( $18 \%$ for CAM5 vs $35 \%$ for CC). In particular, we find that the largest differences in cloud fraction are for the most optically thin low clouds. This is somewhat expected, given that cumulus are going to be a function of the diagnostic shallow convection scheme, with highly uncertain radiative properties.

The cloud radiative kernels show that the model TOA radiation has a larger sensitivity to changes in low cloud fraction, with a tendency for stronger cooling by low clouds in CAM5 (Fig. 3, middle panels). Differences in the day and night cloud fractions contribute to the bright bias in the model CRK for stratocumulus. When considering the daytime-only radiative effects (Fig. 5), the differences between CAM5 and CC stratocumulus are reduced $\left(\sim 70 \mathrm{~W} \mathrm{~m}^{-2}\right.$ bias).

In terms of cloud properties, we find that CAM5 have broadly realistic ranges of LWP although effective radius tends to occupy a narrower range of smaller values (Fig. 6). When considering the microphysics for low clouds on the whole, the LWP-normalized-by-cloud fraction is larger for single-layer low clouds in CAM5, and suggests too large a water path for the given cloud fraction. In addition, CAM5 low clouds have a higher mean optical depth relative to CC (Fig. 7, left panels), given less cumulus and more stratus. Overall, the PDFs of low cloud optical depth and microphysics show less variability in the modeled low cloud types, such that the cooling in the model is produced by a narrower range of clouds than in the observations (Fig. 7, right panels).

Stratocumulus is the most commonly occurring singlelayer cloud type, and the cloud type that is most important radiatively, in both CAM5 and CC. While stratocumulus clouds are responsible for the majority of cooling in both the observations $\left(-25 \mathrm{~W} \mathrm{~m}^{-2}\right)$ and model $\left(-33 \mathrm{~W} \mathrm{~m}^{-2}\right)$, there are compensating errors in CAM5 that lead to this result. For instance, the occurrence of single-layer stratocumulus in CAM5 is just $60 \%$ of what it is in the CC observations (17\% for CAM5 vs $28 \%$ for CC), while the net cooling for stratocumulus, per change in cloud fraction, is 2 times as large in the model $\left(-1.87 \mathrm{~W} \mathrm{~m}^{-2} \%^{-1}\right)$ relative to $\mathrm{CC}$ retrieval $\left(-0.91 \mathrm{~W} \mathrm{~m}^{-2} \%^{-1}\right)$. This factor-of-2 difference $\left(\sim 90 \mathrm{~W} \mathrm{~m}^{-2}\right.$ bias) in the CRKs for stratocumulus has implications for the modeled cloud feedbacks, which result largely from changes in the low cloud fraction. More specifically, the state-dependent bias in the model CRK will result in an overly sensitive tropical low cloud feedback. The CRE tends to asymptote to a minimum value beyond optical depth $\sim 15$-right in the middle range of the stratocumulus bin. At these higher optical depths, the model CRK is overly sensitive to changes in occurrence because changes to optical depth (water path and effective radius) are less efficient at changing the CRE.

The total CAM5 cooling exhibited by single-layer low clouds in the east Pacific region is too large $\left(-43 \mathrm{~W} \mathrm{~m}^{-2}\right.$ for CAM5 vs $-32 \mathrm{~W} \mathrm{~m}^{-2}$ for CC), produced by low clouds that are too bright (Fig. 5) and much too few ( $29 \%$ for CAM5 vs $42 \%$ for CC). These differences arise as a result of compensating effects in the model that may be due to the complex interaction of the diagnostic shallow convective parameterization in CAM5 (which has diagnostic LWP and a fixed assumption about effective radius) with the two-moment stratiform microphysics. The discrepancies we find between the observations and CAM5 for tropical low clouds suggest that the low cloud feedback from this generation of models remains uncertain and is likely too large, due in part to the diurnal variations. Since the simulated clouds tend to have optical depths that are too large, the most efficient path to a changed forcing is via changes to cloud occurrence. The real world seems to be less sensitive to changes in coverage because the optical depth distribution exists more in the range where changes to optical depth can change the cloud radiative forcing. Therefore, changes to bulk microphysics in nature could play a greater role in changing the forcing as the climate 
warms. Since low clouds are a source of so much spread in climate sensitivity, improving the representations of these clouds could reduce the uncertainty in climate projections. CAM6 has attempted to remedy this problem with a more advanced scheme for shallow turbulence (Bogenschutz et al. 2013) that better couples shallow cumulus motions with the boundary layer and prognostic stratiform microphysics. It will be interesting to see if this improves the representation of this critical region, and it has been shown to affect cloud feedbacks (Gettelman et al. 2019).

Acknowledgments. The A-Train data used in this study were obtained through the public CloudSat data archive at the Cooperative Institute for Research in the Atmosphere/Colorado State University. The authors acknowledge the reviewers for their help with improving the paper. Support for this work was provided by a series of NASA Grants: NNX13AQ34G, NNX10AM42G, NNX15AK17G, and 80NSSC19K1251. The National Center for Atmospheric Research is sponsored by the U.S. National Science Foundation.

\section{REFERENCES}

Andrews, T., J. M. Gregory, M. J. Webb, and K. E. Taylor, 2012: Forcing, feedbacks and climate sensitivity in CMIP5 coupled atmosphere-ocean climate models. Geophys. Res. Lett., 39, L09712, https://doi.org/10.1029/2012GL051607.

Berry, E., G. G. Mace, and A. Gettelman, 2019: Using A-Train observations to evaluate cloud occurrence and radiative effects in the Community Atmosphere Model during the Southeast Asia summer monsoon. J. Climate, 32, 4145-4165, https://doi.org/10.1175/JCLI-D-18-0693.1.

Bogenschutz, P. A., A. Gettelman, H. Morrison, V. E. Larson, C. Craig, and D. P. Schanen, 2013: Higher-order turbulence closure and its impact on climate simulations in the Community Atmosphere Model. J. Climate, 26, 9655-9676, https://doi.org/ 10.1175/JCLI-D-13-00075.1.

Bony, S., and J.-L. Dufresne, 2005: Marine boundary layer clouds at the heart of tropical cloud feedback uncertainties in climate models. Geophys. Res. Lett., 32, L20806, https://doi.org/ 10.1029/2005GL023851.

Bretherton, C. S., and S. Park, 2009: A new moist turbulence parameterization in the Community Atmosphere Model. J. Climate, 22, 3422-3448, https://doi.org/10.1175/2008JCLI2556.1.

Caldwell, P. M., M. D. Zelinka, K. E. Taylor, and K. Marvel, 2016: Quantifying the sources of intermodel spread in equilibrium climate sensitivity. J. Climate, 29, 513-524, https://doi.org/ 10.1175/JCLI-D-15-0352.1.

Ceppi, P., F. Brient, M. D. Zelinka, and D. L. Hartmann, 2017: Feedback mechanisms and their representation in global climate models. Wiley Interdiscip. Rev.: Climate Change, 8, e465, https://doi.org/10.1002/wcc.465.

Chepfer, H., S. Bony, D. Winker, M. Chiriaco, J.-L. Dufresne, and G. Seze, 2008: Use of CALIPSO lidar observations to evaluate the cloudiness simulated by a climate model. Geophys. Res. Lett., 35, L15704, https://doi.org/10.1029/ 2008GL034207.
Christensen, M. W., G. L. Stephens, and M. D. Lebsock, 2013: Exposing biases in retrieved low cloud properties from CloudSat: A guide for evaluating observations and climate data. J. Geophys. Res. Atmos., 118, 12120-12131, https:// doi.org/10.1002/2013JD020224.

Collins, W. D., 2001: Parameterization of generalized cloud overlap for radiative calculations in general circulation models. J. Atmos. Sci., 58, 3224-3242, https://doi.org/10.1175/15200469(2001)058<3224:POGCOF>2.0.CO;2.

Deng, M., G. G. Mace, Z. Wang, and E. Berry, 2015: CloudSat 2C-ICE product update with a new $Z_{e}$ parameterization in lidar-only region. J. Geophys. Res. Atmos., 120, 12 198-12 208, https://doi.org/10.1002/2015JD023600.

Dobrowalski, G., and S. Tanelli, 2019: Level 2B-TB94 process description and interface control document. California Institute of Techology Jet Propulsion Laboratory CloudSat Project Doc., 9 pp., http://www.cloudsat.cira.colostate.edu/sites/default/files/ products/files/2B-TB94_PDICD.P1_R05.rev0_pdf.

Dolinar, E. K., X. Dong, B. Xi, J. H. Jiang, and H. Su, 2015: Evaluation of CMIP5 simulated clouds and TOA radiation budgets using NASA satellite observations. Climate Dyn., 44, 2229-2247, https://doi.org/10.1007/s00382-014-2158-9.

Dufresne, J.-L., and S. Bony, 2008: An assessment of the primary sources of spread of global warming estimates from coupled atmosphere-ocean models. J. Climate, 21, 5135-5144, https:// doi.org/10.1175/2008JCLI2239.1.

Engström, A., F. A.-M. Bender, and J. Karlsson, 2014: Improved representation of marine stratocumulus cloud shortwave radiative properties in the CMIP5 climate models. J. Climate, 27, 6175-6188, https://doi.org/10.1175/JCLI-D-13-00755.1.

Flamant, C., J. Pelon, D. Hauser, C. Quentin, W. M. Drennan, G. Gohin, B. Chapron, and J. Gourrion, 2003: Analysis of surface wind and roughness length evolution with fetch using a combination of airborne lidar and radar measurements. J. Geophys. Res., 108, 8058, https://doi.org/10.1029/2002JC001405.

Fu, Q., 1996: An accurate parameterization of the solar radiative properties of cirrus clouds for climate models. J. Climate, $\mathbf{9}$, 2058-2082, https://doi.org/10.1175/1520-0442(1996)009<2058: AAPOTS $>2.0 . \mathrm{CO} ; 2$.

, P. Yang, and W. B. Sun, 1998: An accurate parameterization of the infrared radiative properties of cirrus clouds for climate models. J. Climate, 11, 2223-2237, https://doi.org/10.1175/ 1520-0442(1998)011<2223:AAPOTI >2.0.CO;2.

Gettelman, A., and S. C. Sherwood, 2016: Processes responsible for cloud feedback. Curr. Climate Change Rep., 2, 179-189, https://doi.org/10.1007/S40641-016-0052-8.

— and Coauthors, 2019: High climate sensitivity in the Community Earth System Model version 2 (CESM2). Geophys. Res. Lett., 46, 8329-8337, https://doi.org/10.1029/2019GL083978.

Gordon, N. D., and S. A. Klein, 2014: Low-cloud optical depth feedback in climate models. J. Geophys. Res. Atmos., 119, 6052-6065, https://doi.org/10.1002/2013JD021052.

Haney, C. O., 2013: Cloud drop effective radius for trade wind cumuli observed during RICO by aircraft and MODIS. M.S. thesis, Dept. of Atmospheric Sciences, University of Illinois at Urbana-Champaign, $89 \mathrm{pp}$.

Haynes, J. M., T. S. L'Ecuyer, G. L. Stephens, S. D. Miller, C. Mitrescu, N. B. Wood, and S. Tanelli, 2009: Rainfall retrieval over the ocean with spaceborne $\mathrm{W}$-band radar. J. Geophys. Res., 114, D00A22, https://doi.org/10.1029/ 2008JD009973.

Henderson, D. S., T. L'Ecuyer, G. Stephens, P. Partain, and M. Sekiguchi, 2013: A multisensor perspective on the radiative 
impacts of clouds and aerosols. J. Appl. Meteor. Climatol., 52, 853-871, https://doi.org/10.1175/JAMC-D-12-025.1.

Hill, P. G., J. C. Chiu, R. P. Allan, and J.-D. Chern, 2018: Characterizing the radiative effect of rain using a global ensemble of cloud resolving simulations. J. Adv. Model. Earth Syst., 10, 2453-2470, https://doi.org/10.1029/2018MS001415.

$\mathrm{Hu}, \mathrm{Y}$., and Coauthors, 2007: The depolarization-attenuated backscatter relation: $C A L I P S O$ lidar measurements vs. theory. Opt. Express, 15, 5327-5332, https://doi.org/10.1364/OE.15.005327.

Iacono, M. J., J. S. Delamere, E. J. Mlawer, M. W. Shephard, S. A. Clough, and W. D. Collins, 2008: Radiative forcing by longlived greenhouse gases: Calculations with the AER radiative transfer models. J. Geophys. Res., 113, D13103, https://doi.org/ 10.1029/2008JD009944.

Jakob, C., and S. A. Klein, 1999: The role of vertically varying cloud fraction in the parametrization of microphysical processes in the ECMWF model. Quart. J. Roy. Meteor. Soc., 125, 941-965, https://doi.org/10.1002/qj.49712555510.

Josset, D., J. Pelon, A. Protat, and C. Flamant, 2008: New approach to determine aerosol optical depth from combined CALIPSO and CloudSat ocean surface echoes. Geophys. Res. Lett., 35, L10805, https://doi.org/10.1029/2008GL033442.

— R. Rogers, J. Pelon, Y. Hu, Z. Liu, A. Omar, and P.-W. Zhai, 2011: CALIPSO lidar ratio retrieval over the ocean. Opt. Express, 19, 18696-18 706, https://doi.org/10.1364/OE.19.018696.

Kato, S., G. L. Smith, and H. W. Barker, 2001: Gamma-weighted discrete ordinate two-stream approximation for computation of domain-averaged solar irradiance. J. Atmos. Sci., 58, 3797-3803, https://doi.org/10.1175/1520-0469(2001)058<3797:GWDOTS $>2$. $0 . \mathrm{CO} ; 2$.

Kay, J. E., and Coauthors, 2012: Exposing global biases in the Community Atmosphere Model (CAM) using satellite observations and their corresponding instrument simulators. J. Climate, 25, 5190-5207, https://doi.org/10.1175/JCLI-D-1100469.1.

Khairoutdinov, M. F., and Y. Kogan, 2000: A new cloud physics parameterization in a large-eddy simulation model of marine stratocumulus. Mon. Wea. Rev., 128, 229-243, https://doi.org/ 10.1175/1520-0493(2000)128<0229:ANCPPI >2.0.CO;2.

Kiehl, J., J. Hack, G. B. Bonan, B. A. Boville, D. L. Williamson, and P. J. Rasch, 1998: The National Center for Atmospheric Research Community Climate Model: CCM3. J. Climate, 11, 1131-1149, https://doi.org/10.1175/1520-0442(1998)011<1131: TNCFAR $>2.0 . \mathrm{CO} ; 2$.

Konsta, D., J.-L. Dufresne, H. Chepfer, A. Idelkadi, and G. Cesana, 2016: Use of A-Train satellite observations (CALIPSO-PARASOL) to evaluate tropical cloud properties in the LMDZ5 GCM. Climate Dyn., 47, 1263-1284, https://doi.org/10.1007/s00382-015-2900-y.

Kratz, D. P., P. W. Stackhouse Jr., S. K. Gupta, A. C. Wilber, P. Sawaengphokhai, and G. R. McGarragh, 2014: The fast longwave and shortwave flux (FLASHFlux) data product: Single-scanner footprint fluxes. J. Appl. Meteor. Climatol., 53, 1059-1079, https://doi.org/10.1175/JAMC-D-13-061.1.

Lauer, A., and K. Hamilton, 2013: Simulating clouds with global climate models: A comparison of CMIP5 results with CMIP3 and satellite data. J. Climate, 26, 3823-3845, https://doi.org/ 10.1175/JCLI-D-12-00451.1.

Li, J., Y. Hu, J. Huang, K. Stamnes, Y. Yi, and S. Stamnes, 2011: A new method for retrieval of the extinction coefficient of water clouds by using the tail of the CALIOP signal. Atmos. Chem. Phys., 11, 2903-2916, https://doi.org/10.5194/acp-11-2903-2011.

Li, J.-L. F., and Coauthors, 2008: Comparisons of satellites liquid water estimates to ECMWF and GMAO analyses, 20th century IPCC AR4 climate simulations, and GCM simulations. Geophys. Res. Lett., 35, L19710, https://doi.org/10.1029/ 2008 GL035427.

— W.-L. Lee, D. E. Waliser, J. P. Stachnik, E. Fetzer, S. Wong, and Q. Yue, 2014: Characterizing tropical Pacific water vapor and radiative biases in CMIP5 GCMs: Observation-based analyses and a snow and radiation interaction sensitivity experiment. J. Geophys. Res. Atmos., 119, 10 981-10 995, https:// doi.org/10.1002/2014JD021924.

—, S. Lee, H.-Y. Ma, G. Stephens, and B. Guan, 2018: Assessment of the cloud liquid water from climate models and reanalysis using satellite observations. Terr. Atmos. Oceanic Sci., 29, 653-678, https://doi.org/10.3319/TAO.2018.07.04.01.

Mace, G. G., 2010: Cloud properties and radiative forcing over the maritime storm tracks of the Southern Ocean and North Atlantic derived from A-Train. J. Geophys. Res., 115, D10201, https://doi.org/10.1029/2009JD012517.

— , and F. J. Wrenn, 2013: Evaluation of the hydrometeor layers in the east and west Pacific within ISCCP cloud-top pressureoptical depth bins using merged CloudSat and CALIPSO data. J. Climate, 26, 9429-9444, https://doi.org/10.1175/JCLID-12-00207.1.

— , and Q. Zhang, 2014: The CloudSat radar-lidar geometrical profile product (RL-GeoProf): Updates, improvements, and selected results. J. Geophys. Res. Atmos., 119, 9441-9462, https://doi.org/10.1002/2013JD021374.

— , and E. Berry, 2017: Using active remote sensing to evaluate cloud-climate feedbacks: A review and a look to the future. Curr. Climate Change Rep., 3, 185-192, https://doi.org/10.1007/ s40641-017-0067-9.

— , and A. Protat, 2018: Clouds over the Southern Ocean as observed from the $\mathrm{R} / \mathrm{V}$ Investigator during CAPRICORN. Part II: The properties of nonprecipitating stratocumulus. J. Appl. Meteor. Climatol., 57, 1805-1823, https://doi.org/ 10.1175/JAMC-D-17-0195.1.

—, Q. Zhang, M. Vaughn, R. Marchand, G. Stephens, C. Trepte, and D. Winker, 2009: A description of hydrometeor layer occurrence statistics derived from the first year of merged Cloudsat and CALIPSO data. J. Geophys. Res., 114, D00A26, https://doi.org/10.1029/2007JD009755.

Marchand, R., G. G. Mace, T. Ackerman, and G. Stephens, 2008: Hydrometeor detection using Cloudsat-An Earth-orbiting 94-GHz cloud radar. J. Atmos. Oceanic Technol., 25, 519-533, https://doi.org/10.1175/2007JTECHA1006.1.

McCoy, D. T., I. Tan, D. L. Hartmann, M. D. Zelinka, and T. Storelvmo, 2016: On the relationships among cloud cover, mixed-phase partitioning, and planetary albedo in GCMs. J. Adv. Model. Earth Syst., 8, 650-668, https://doi.org/10.1002/ 2015MS000589.

Medeiros, B., and L. Nuijens, 2016: Clouds at Barbados are representative of clouds across the trade wind regions in observations and climate models. Proc. Natl. Acad. Sci. USA, 113, E3062-E3070, https://doi.org/10.1073/pnas.1521494113.

Miller, M. A., M. P. Jensen, and E. E. Clothiaux, 1998: Diurnal cloud and thermodynamic variations in the stratocumulus transition regime: A case study using in situ and remote sensors. J. Atmos. Sci., 55, 2294-2310, https://doi.org/10.1175/ 1520-0469(1998)055<2294:DCATVI>2.0.CO;2.

Mlawer, E. J., S. J. Taubman, P. D. Brown, M. J. Iacono, and S. A. Clough, 1997: Radiative transfer for inhomogeneous atmospheres: RRTM, a validated correlated- $k$ model for the longwave.J. Geophys. Res., 102, 16 663-16 682, https://doi.org/ 10.1029/97JD00237. 
Morrison, H., and A. Gettelman, 2008: A new two-moment bulk stratiform cloud microphysics scheme in the Community Atmosphere Model, version 3 (CAM3). Part I: Description and numerical tests. J. Climate, 21, 3642-3659, https://doi.org/ 10.1175/2008JCLI2105.1.

Mülmenstädt, J., O. Sourdeval, J. Delano, and J. Quaas, 2015: Frequency of occurrence of rain from liquid-, mixed-, and icephase clouds derived from A-Train satellite retrievals. Geophys. Res. Lett., 42, 6502-6509, https://doi.org/10.1002/2015GL064604.

Nam, C., S. Bony, J.-L. Dufresne, and H. Chepfer, 2012: The 'too few, too bright' tropical low-cloud problem in CMIP5 models. Geophys. Res. Lett., 39, L21801, https://doi.org/10.1029/2012GL053421.

Neale, R. B., and Coauthors, 2010: Description of the NCAR Community Atmosphere Model (CAM 5.0). NCAR Tech. Note NCAR/TN-486+STR, 268 pp., www.cesm.ucar.edu/ models/cesm1.1/cam/docs/description/cam5_desc.pdf.

Oreopoulos, L., and S. Platnick, 2008: Radiative susceptibility of cloudy atmospheres to droplet number perturbations: 2 . Global analysis from MODIS. J. Geophys. Res., 113, D14S21, https://doi.org/10.1029/2007JD009655.

Painemal, D., and P. Zuidema, 2011: Assessment of MODIS cloud effective radius and optical thickness retrievals over the Southeast Pacific with VOCALS-REx in situ measurements. J. Geophys. Res., 116, D24206, https://doi.org/10.1029/2011JD016155.

Park, S., and C. S. Bretherton, 2009: The University of Washington shallow convection and moist turbulence schemes and their impact on climate simulations with the Community Atmosphere Model. J. Climate, 22, 3449-3469, https://doi.org/10.1175/2008JCLI2557.1.

Platnick, S., and Coauthors, 2017: The MODIS cloud optical and microphysical products: Collection 6 updates and examples from Terra and Aqua. IEEE Trans. Geosci. Remote Sens., 55, 502-525, https://doi.org/10.1109/TGRS.2016.2610522.

Qu, X., A. Hall, S. A. Klein, and P. M. Caldwell, 2014: On the spread of changes in marine low cloud cover in climate model simulations of the 21st century. Climate Dyn., 42, 2603-2626, https://doi.org/10.1007/s00382-013-1945-z.

Rossow, W. B., and R. A. Schiffer, 1999: Advances in understanding clouds from ISCCP. Bull. Amer. Meteor. Soc., 80, 2261-2288, https://doi.org/10.1175/1520-0477(1999)080<2261: AIUCFI $>2.0 . \mathrm{CO} ; 2$.

Rozendaal, M., C. B. Leovy, and S. A. Klein, 1995: An observational study of diurnal variations of marine stratiform cloud. J. Climate, 8, 1795-1809, https://doi.org/10.1175/1520-0442(1995)008<1795: AOSODV $>2.0 . \mathrm{CO} ; 2$.

Sherwood, S. C., S. Bony, and J.-L. Dufresne, 2014: Spread in model climate sensitivity traced to atmospheric convective mixing. Nature, 505, 37-42, https://doi.org/10.1038/nature12829.

Slingo, J. M., 1989: A GCM parameterization for the shortwave radiative properties of water clouds. J. Atmos. Sci., 46, 1419-1427, https:// doi.org/10.1175/1520-0469(1989)046<1419:AGPFTS>2.0.CO;2.

Stephens, G. L., 1978: Radiation profiles in extended water clouds. II: Parameterization schemes. J. Atmos. Sci., 35, 2123-2132, https://doi.org/10.1175/1520-0469(1978)035<2123:RPIEWC > 2.0.CO;2.

- D. Winker, J. Pelon, C. Trepte, D. Vane, C. Yuhas, T. L'Ecuyer, and M. Lebsock, 2018: CloudSat and CALIPSO within the A-Train: Ten years of actively observing the Earth system. Bull. Amer. Meteor. Soc., 99, 569-581, https://doi.org/ 10.1175/BAMS-D-16-0324.1.
- and Coauthors, 2019: Cloud physics from space. Quart. J. Roy. Meteor. Soc., 145, 2854-2875, https://doi.org/10.1002/qj.3589.

Stevens, B., and S. Bony, 2013: What are climate models missing? Science, 340, 1053-1054, https://doi.org/10.1126/science.1237554.

Suzuki, K., G. Stephens, A. Bodas-Salcedo, M. Wang, J.-C. Golaz, T. Yokohata, and T. Koshiro, 2015: Evaluation of the warm rain formation process in global models with satellite observations. J. Atmos. Sci, 72, 3996-4014, https://doi.org/10.1175/JAS-D-14-0265.1.

Tanelli, S., S. L. Durden, K. S. Pak, D. G. Reinke, P. Partain, J. M. Haynes, and R. T. Marchand, 2008: CloudSat's cloud profiling radar after two years in orbit: Performance, calibration, and processing. IEEE Trans. Geosci. Remote Sens., 46, 3560-3573, https://doi.org/10.1109/TGRS.2008.2002030.

Toon, O. B., C. P. McKay, T. P. Ackerman, and K. Santhanam, 1989: Rapid calculation of radiative heating rates and photodissociation rates in inhomogeneous multiple scattering atmospheres. J. Geophys. Res., 94, 16287-16301, https://doi.org/ 10.1029/JD094iD13p16287.

Turner, D. D., and Coauthors, 2007: Thin liquid water clouds: Their importance and our challenge. Bull. Amer. Meteor. Soc., 88, 177-190, https://doi.org/10.1175/BAMS-88-2-177.

Vial, J., J.-L. Dufresne, and S. Bony, 2013: On the interpretation of inter-model spread in CMIP5 climate sensitivity estimates. Climate Dyn., 41, 3339-3362, https://doi.org/10.1007/s00382013-1725-9.

- S. Bony, J.-L. Dufresne, and R. Roehrig, 2016: Coupling between lower-tropospheric convective mixing and low-level clouds: Physical mechanisms and dependence on convection scheme. J. Adv. Model. Earth Syst., 8, 1892-1911, https:// doi.org/10.1002/2016MS000740.

Wang, H., and W. Su, 2013: Evaluating and understanding top of the atmosphere cloud radiative effects in Intergovernmental Panel on Climate Change (IPCC) Fifth Assessment Report (AR5) Coupled Model Intercomparison Project Phase 5 (CMIP5) models using satellite observations. J. Geophys. Res. Atmos., 118, 683-699, https://doi.org/10.1029/2012JD018619.

Winker, D., and Coauthors, 2010: The CALIPSO mission. Bull. Amer. Meteor. Soc., 91, 1211-1230, https://doi.org/10.1175/ 2010BAMS3009.1.

, H. Chepfer, V. Noel, and X. Cai, 2017: Observational constraints on cloud feedbacks: The role of active satellite sensors. Surv. Geophys., 38, 1483-1508, https://doi.org/10.1007/s10712017-9452-0.

Wood, R., 2012: Stratocumulus clouds. Mon. Wea. Rev., 140, 2373 2423, https://doi.org/10.1175/MWR-D-11-00121.1.

Zelinka, M. D., S. A. Klein, and D. L. Hartmann, 2012: Computing and partitioning cloud feedbacks using cloud property histograms. Part I: Cloud radiative kernels. J. Climate, 25, 3715-3735, https://doi.org/10.1175/JCLI-D-11-00248.1.

$\longrightarrow$, C. Zhou, and S. A. Klein, 2016: Insights from a refined decomposition of cloud feedbacks. Geophys. Res. Lett., 43, 92599269, https://doi.org/10.1002/2016GL069917.

Zhang, M. H., and Coauthors, 2005: Comparing clouds and their seasonal variations in 10 atmospheric general circulation models with satellite measurements. J. Geophys. Res., 110, D15S02, https://doi.org/10.1029/2004JD005021.

Zhao, M., and Coauthors, 2016: Uncertainty in model climate sensitivity traced to representations of cumulus precipitation microphysics. J. Climate, 29, 543-560, https://doi.org/10.1175/ JCLI-D-15-0191.1. 